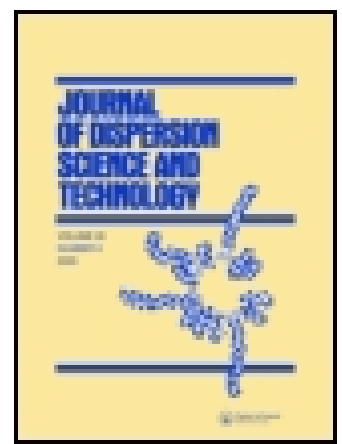

Journal of Dispersion Science and Technology

ISSN: 0193-2691 (Print) 1532-2351 (Online) Journal homepage: http://www.tandfonline.com/loi/ldis20

\title{
Apparent viscosity characteristics and prediction model of an unstable oil-in-water or water-in-oil dispersion system
}

Jian Zhang \& Jing-Yu Xu

To cite this article: Jian Zhang \& Jing-Yu Xu (2018): Apparent viscosity characteristics and prediction model of an unstable oil-in-water or water-in-oil dispersion system, Journal of Dispersion Science and Technology, DOI: 10.1080/01932691.2018.1527229

To link to this article: https://doi.org/10.1080/01932691.2018.1527229

Submit your article to this journal 주

View Crossmark data ¿ 


\title{
Apparent viscosity characteristics and prediction model of an unstable oil-in- water or water-in-oil dispersion system
}

\author{
Jian Zhang ${ }^{\mathrm{a}, \mathrm{b}}$ and Jing-Yu $\mathrm{Xu}^{\mathrm{a}, \mathrm{b}}$

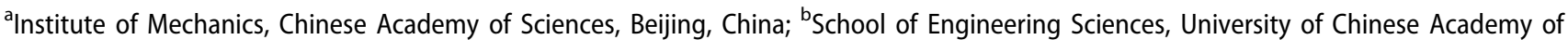 \\ Sciences, Beijing, China
}

\begin{abstract}
A series of theoretical analysis and experimental measurements were done to analyze the characteristic of the apparent viscosity of oil-water unstable mixtures which display the similar distributions as the mixtures in pipeline flow. Based on the experimental results, it can be concluded that the unstable oil-water dispersed mixtures are always show the characteristic of non-Newtonian fluid. The shear rate has a great influence on the apparent viscosity, particular for the water-in-oil mixtures. The effect of dispersed phase volume fraction on the apparent viscosity of the unstable mixtures displays the similar rules as the stable emulsions. Also, the influences of the dispersed phase distribution and viscosity on the apparent viscosity were studied through the corresponded experiments systematically. Furthermore, a new kind of prediction model was obtained in the present study. The unstable and non-Newtonian fluid characteristics of oil-water two-phase dispersed mixtures were considered in this model to improve their range of application and the prediction accuracy. Moreover, this kind of apparent viscosity prediction model was validated by using the experimental data from some other literatures including different kinds of oils such as white oil and crude oil, and the average deviation was always less than $9 \%$ which was a great accuracy of apparent viscosity prediction.
\end{abstract}

\section{GRAPHICAL ABSTRACT}

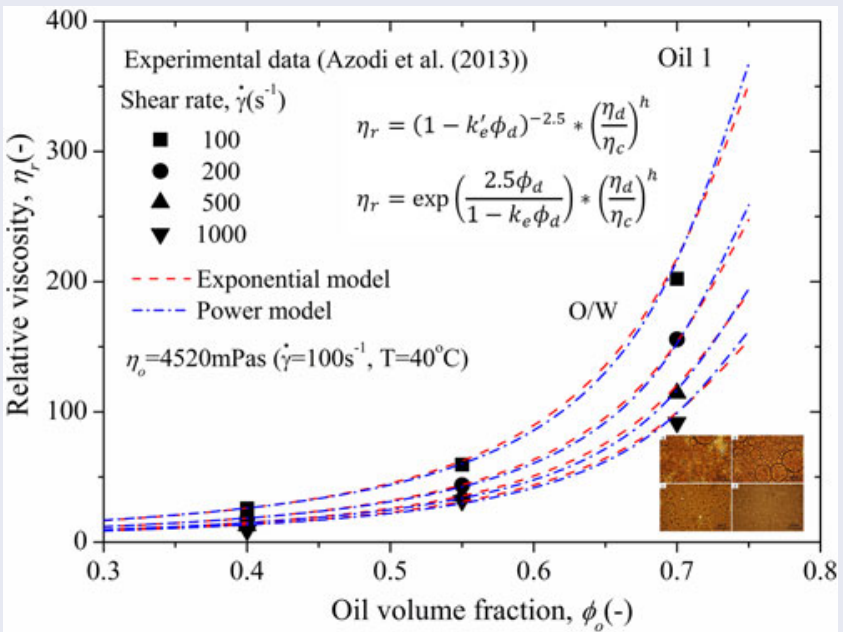

\section{ARTICLE HISTORY}

Received 12 July 2018

Accepted 15 September 2018

\section{KEYWORDS}

Unstable mixtures; apparent viscosity; non-Newtonian fluid; prediction model

\section{Introduction}

Oil water two-phase flow in pipeline is becoming more and more common in petroleum engineering such as oil exploitation and transportation. It is important to predict the pressure gradient in oil-water two-phase flow precisely in order to design the system of petroleum engineering optimally. ${ }^{[1-3]}$ There are two common multiphase flow models, separatedfluid model and homogenous-fluid model, to solve these problems above. The oil and water are treated as single fluids, and the interfacial effects included momentum and energy exchange should be considered in the separated-fluid multiphase flow model. Differently, the oil and water are treated as one homogenous mixture and the interfacial effects are hidden in the homogenous-fluid multiphase flow model. ${ }^{[4-6]}$ In the petroleum engineering, the oil and water are always displayed as dispersed mixtures due to the effect of high shearing and nature surfactants included resins, 
Table 1. Representative models for the apparent viscosity of dispersed mixtures in the literature.

\begin{tabular}{|c|c|c|c|}
\hline Authors & Models and correlations & Category & Remarks \\
\hline Einstein $(1906)^{[16]}$ & $\eta_{r}=1+2.5 \phi_{d}$ & Linear & $\begin{array}{l}\text { Adapted to dilute (only up to } 2 \% \text { volume fraction) and monodis- } \\
\text { persed system. }\end{array}$ \\
\hline Taylor $(1932)^{[17]}$ & $\eta_{r}=1+\phi_{d}\left(\frac{\eta_{c}+2.5 \eta_{d}}{\eta_{c}+\eta_{d}}\right)$ & Linear & $\begin{array}{l}\text { Considered the effect of viscosity of the dispersed and continu- } \\
\text { ous phases. }\end{array}$ \\
\hline Richardson $(1933)^{[18]}$ & $\eta_{r}=\exp \left(C \phi_{d}\right)$ & Exponential & $\begin{array}{l}\text { Considered the non-Newtonian behavior and the first exponential } \\
\text { relationship between } \eta_{r} \text { and } \Phi_{d} \text {. }\end{array}$ \\
\hline Guth \& Simha $(1936)^{[19]}$ & $\eta_{r}=1+2.5 \phi_{d}+14.1 \phi_{d}^{2}$ & Power & $\begin{array}{l}\text { Take into account the interaction between droplets to extend the } \\
\text { volume range of the dispersed phase. }\end{array}$ \\
\hline Mooney $(1951)^{[20]}$ & $\eta_{r}=\exp \left(\frac{2.5 \phi_{d}}{1-k \phi_{d}}\right)$ & Exponential & Extension of Richardson model, $1.35<k<1.91$ \\
\hline Brinkman $(1952)^{[21]}$ & $\eta_{r}=\left(1-\phi_{d}\right)^{-2.5}$ & Power & Extension of Einstein's model to fit a high concentration emulsion \\
\hline Krirger \& Dougherty $(1959)^{[22]}$ & $\eta_{r}=\left(1-\frac{\phi_{d}}{\phi_{m}}\right)^{-2.5 \phi_{m}}$ & Power & $\begin{array}{l}\text { Introduced the maximum packing concentration of the dispersed } \\
\text { phase }\left(\Phi_{m}\right) \text {. }\end{array}$ \\
\hline Pal \& Rhodes $(1985)^{[23]}$ & $\eta_{r}=\left[1+\frac{1.342 \phi_{d} / \phi_{\eta_{r}=100}}{1.194-\phi_{d} / \phi_{\eta_{r}=100}}\right]^{2.226}$ & Power & $\begin{array}{l}\text { Introduced the dispersed phase volume fraction at relative viscosity } \\
\text { is equal to } 100 \text {. }\end{array}$ \\
\hline Ronningsen $(1995)^{[24]}$ & $\eta_{r}=\exp \left(C_{1}+C_{2} T+C_{3} \phi_{d}+C_{4} T \phi_{d}\right)$ & Exponential & Take into account the effect of shear rate and temperature. \\
\hline \multirow[t]{2}{*}{ Pal $(2001)^{[25]}$} & $\eta_{r}\left[\frac{2 \eta_{r}+5 k}{2+5 k}\right]^{1.5}=\exp \left(\frac{2.5 \phi_{d}}{1-\phi_{d} / \phi_{m}}\right)$ & Exponential & $\begin{array}{l}\text { Developed from Taylor's model for the concentrated emulsions } \\
\text { using the effective medium method. }\end{array}$ \\
\hline & $\eta_{r}\left[\frac{2 \eta_{r}+5 k}{2+5 k}\right]^{1.5}=\left(1-\frac{\phi_{d}}{\phi_{m}}\right)^{-2.5 \phi_{m}}$ & Power & \\
\hline Dan \& Jing $(2006)^{[26]}$ & $\eta_{r}=\left(1-k_{e} \phi_{d}\right)^{-2.5}$ & Power & $\begin{array}{l}\text { Valid for water-in-crude oil emulsion which always displayed as } \\
\text { non-Newtonian fluid. }\end{array}$ \\
\hline Wen \& Zhang $(2016)^{[27]}$ & $\eta_{r}=1+\left(\frac{\eta_{c}+2.5 \eta_{d}}{\eta_{c}+\eta_{d}}\right)\left(\phi_{d}+\phi_{e}\right)$ & Linear & $\begin{array}{l}\text { Valid for the crude oil-water mixture with high water fraction, } \Phi_{e} \\
\text { is the emulsified water fraction. }\end{array}$ \\
\hline
\end{tabular}

asphaltenes and wax particles containing in the crude oil. Therefore, the homogenous-fluid multiphase flow model is more suitable to treat the multiphase flow problem which is always exist in the petroleum engineering and perform as dispersed flow patterns. ${ }^{[7-9]}$

In the homogenous-fluid model, the mixture of oil and water is seen as one homogenous fluid which means that the mixture is an isotropic fluid. So, the apparent viscosity of the oil-water dispersed mixture should be known if we want to obtain the pressure gradient and other flow parameters in oil-water two-phase pipeline flow through the homogenous-fluid model. Actually, a flowing oil-water system usually does not perform as a stable emulsion, but in the form of an unstable mixture with different continuous phases, significantly differing from a stable emulsion. ${ }^{[10,11]}$ And, the unstable oil-water mixtures are always shown as non-Newtonian fluid with different characteristics of shear thinning, thixotropy and yield stress due to its unstable characteristics and different dispersed phase distribution. ${ }^{[12,13]}$ It is important to obtain the apparent viscosity of the unstable oil-water mixture to predict the pressure gradient in pipeline flow, but it is difficult because of the complex rheological characteristics of the unstable oilwater mixtures.

The apparent viscosity of emulsions (stable and unstable) is affected by a number of factors: viscosity of continuous phase $\left(\eta_{c}\right)$, volume fraction of dispersed phase $\left(\phi_{d}\right)$, droplet distribution of dispersed phase $\left(d_{d}\right)$, viscosity of dispersed phase $\left(\eta_{d}\right)$, temperature $(T)$, shear rate $(\dot{\gamma})$, density of continuous phase $\left(\rho_{c}\right)$, density of dispersed phase $\left(\rho_{d}\right)$. And, these factors can influence each other greatly. ${ }^{[14,15]}$

$$
\eta_{a}=f\left(\phi_{d}, \eta_{c}, \eta_{d}, d_{d}, T, \dot{\gamma}, \rho_{c}, \rho_{d}\right)
$$

A large number of apparent viscosity equations and correlations have been developed in the previous studies from Einstein. ${ }^{[16]}$ These models can be grouped into three main categories generally, namely, linear, exponential and power function models. Some representative models including their special features are displayed in Table 1. The detailed list of almost all models can be found in Zhang et al. ${ }^{[12]}$ and Kundu et al. ${ }^{[28]}$ Most of the existing apparent viscosity models are based on the fact that the apparent viscosity of the emulsions depends on the viscosity of continuous phase, and are usually reported in terms of relative viscosity, $\eta_{r}$ (the ratio of the apparent viscosity of emulsion to the viscosity of continuous phase). ${ }^{[2]}$ The effect of dispersed phase volume fraction $\left(\Phi_{d}\right)$, viscosity of continuous phase $\left(\eta_{c}\right)$, viscosity of dispersed phase $\left(\eta_{d}\right)$, temperature $(T)$ and shear rate $\left(\gamma^{\prime}\right)$ were considered separately with kinds of relations in these models and equations, and some factors such as shear rate were implied in the undermined parameters. However, these apparent viscosity prediction models were obtained from the stable emulsions, and the viscosity ratio of dispersed phase to continuous phase is less than 10. The influences of unstable characteristics including dispersed phase distribution and droplets coalescence, which are always display in oil-water two-phase dispersed mixtures flow in pipeline, were not considered. Therefore, it is difficult to predict the apparent viscosity of unstable oil-water dispersed mixtures precisely, and the prediction models always underestimate the value of apparent viscosity. ${ }^{[12]}$ In this work, the effect of unstable characteristics on the apparent viscosity of oil-water dispersed mixtures will be studied to improve the theory of apparent viscosity prediction.

To improve the pipeline transportation of oil-water twophase dispersed mixtures, the theoretical analysis and experimental measurements were done to analyze the effects of every factor, which were showed above, on the apparent viscosity of an oil-in-water or water-in-oil unstable emulsion systematically for the first time. In order to obtain a universal consequence, several kinds of oils were used as the oil phase for the two-phase dispersed mixtures including two industry white oils and two crude oils, where their viscosities are in the range from $30 \mathrm{mPas}$ to $5439 \mathrm{mPas}$ at $30^{\circ} \mathrm{C}$. 
Table 2. Physical properties of experimental oils $\left(T=30^{\circ} \mathrm{C}, P=101.325 \mathrm{kPa}, \dot{\gamma}=10 \mathrm{~s}^{-1}\right)$.

\begin{tabular}{lccccccc} 
& & & & \multicolumn{4}{c}{ SARA analysis (wt.\%) } \\
\cline { 5 - 8 } Oil types & Density $\left(\mathrm{kg} / \mathrm{m}^{3}\right)$ & Viscosity (mPas) & Surface tension (N/m) & Saturates & Aromatics & Resins & Asphaltenes \\
\hline White oil A & 840 & 30 & 0.031 & 98.3 & 1.7 & - & - \\
White oil B & 840 & 60 & 0.031 & 98.6 & 1.4 & - & - \\
Crude oil A & 955 & 5439 & 0.035 & 33.2 & 26.2 & 37.2 & 3.4 \\
Crude oil B & 920 & 242 & 0.032 & 52.7 & 27.3 & 18.4 & 1.6 \\
\hline
\end{tabular}

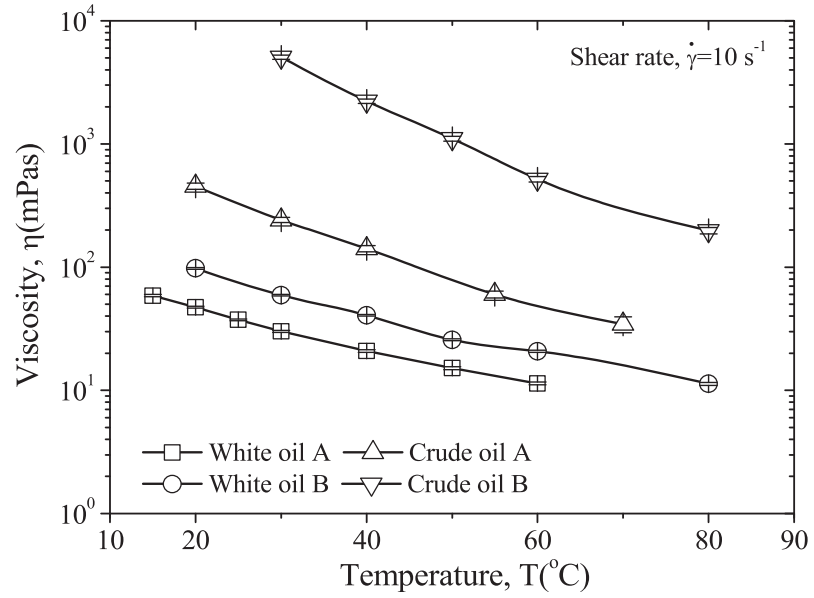

Figure 1. Viscosity vs. temperature of four experimental oils.

And, a new kind of apparent viscosity prediction model was obtained through the experiments in the present study. It is more accurate and suitable for the unstable oil-water dispersed mixtures than previous models. The average deviation is always less than 9\% which is a great accuracy of apparent viscosity prediction than the previous models. The unstable characteristic of oil-water two-phase dispersed mixtures, which has not been researched in previous models, was considered in these models to improve their range of application and the prediction accuracy. Moreover, this kind of apparent viscosity prediction model was validated by using the experimental data from some other literatures included different kinds of oils such as white oil and crude oil to verify their scopes of application. Finally, the given apparent prediction model was proposed to calculate the apparent viscosity of different kinds of oil-water dispersed mixtures including stable and unstable emulsions.

\section{Experimental}

\section{Materials}

In order to obtain a universal consequence, several kinds of oils were used as the oil phase for the two-phase dispersed mixtures including two industry white oils and two crude oils. The industry white oil is a refined mineral oil that consists of the saturated hydrocarbons, which was produced at Yanshan Petrochemical Company in China and it is always classified by the viscosity. Two different white oils, named White oil A and B, were chosen to investigate the effect of dispersed viscosity on the apparent viscosity of oil-in-water dispersed mixtures. And, these chosen white oils display as Newtonian fluid. Two crude oils produced in Sui-zhong and Bo-hai oilfields in China, named Crude oil A and B, were used in this study respectively, which shows very different physical properties including density and viscosity. Also, these chosen crude oils display as non-Newtonian fluid with different degrees of shear thinning characteristics. The physical properties of these experimental oils are listed in Table 2 , and the rules of viscosity vs. temperature is displayed in Figure 1. Tap water is used as the water phase, and its density is $998 \mathrm{~kg} / \mathrm{m}^{3}$ at $30^{\circ} \mathrm{C}$.

\section{Preparation of dispersed mixtures}

In this study, series kinds of stable and unstable oil-water two-phase dispersed mixtures were prepared in order to consider the effect of dispersed phase distribution and different unstable characteristics. The mixtures were prepared with different oil volume fractions in the range of $0-1$. A three-blade stirrer was used to homogenize the oil-water two-phase solutions at a fixed speed $1000 \mathrm{r} / \mathrm{min}$. And, several different stirring times, including $90 \mathrm{~s}, 180 \mathrm{~s}, 300 \mathrm{~s}, 600 \mathrm{~s}$, $1200 \mathrm{~s}$, was chosen to obtain the series of experimental mixtures with different dispersed phase distribution and unstable characteristics. There is not any emulsifier added on the mixtures in order to obtain the similar stability of the oil-water mixtures flowing in pipeline. The oil-water two-phase mixtures will be more stable with the increasing stirring time in the present study.

The microstructure of the prepared oil-water two-phase dispersed mixtures was obtained using a trinocular optical microscope Olympas BX43 with an adapted CCD camera ProgRes C5. The dispersed phase distribution was measured through the relative microstructure pictures. The measurement of the precipitated water from the oil-water dispersed mixtures as the increasing standing time after preparation was used to measure their unstable characteristics quantitatively.

\section{Rheological measurements}

Rheological characteristics of oil-water dispersed mixtures, including apparent viscosity and relative relationship, were carried out on a HAAKE RS6000 Rheometer with a coaxial cylinder sensor system named Z38 and Z43. The diameter of the rotor is $38 \mathrm{~mm}$, and the gap width between rotor and cup is $2.5 \mathrm{~mm}$ which is big enough compared to the droplet diameter of the dispersed phase. A variety of temperature control units is available to handle experimental temperatures ranging from -40 to $140^{\circ} \mathrm{C}$ accurately. In this study, the experimental temperature was always handled in the range from 10 to $90^{\circ} \mathrm{C}$ which was common on the petroleum industry. After loading the sample on the sensor system, the corresponding measurement was started immediately to avoid the unstable mixtures 
stratified. The phase distribution of unstable mixture was monitored through the high-speed camera in the process of the similar experiments with a clear cup which has the same size of Z43.

All of the measurements were conducted under the CR model where the shear rate was set in advance and the corresponded shear stress was measured. At least, three replicates of each test were performed in order to improve the reliability of the consequences. Furthermore, this rheometer has a range of shear rate from 0.001 to $1500 \mathrm{~s}^{-1}$ and a range of viscosity from 0.5 to $10^{6} \mathrm{mPas}$.

\section{Experimental results and discussion}

According to previous study, ${ }^{[12]}$ the constitutive relations of the oil and water two-phase dispersed mixtures can be analyzed by using the Power law fluid model (Ostwald-de Waele model). Therefore, the rheological measurement results will be fitted by this model to describe the nonNewtonian fluid characteristics in this study quantificationally. The Power law fluid model is expressed by using two parameters in the following equation:

$$
\tau=m(\dot{\gamma})^{n}
$$

Here, $\tau$ is the shear stress in $\mathrm{Pa}, \dot{\gamma}$ is the shear rate in $\mathrm{s}^{-1}, m$ is the fluid consistency coefficient in $\mathrm{Pas}^{\mathrm{n}}$ and $n$ is the flow behavior index which describes the degree of nonNewtonian fluid characteristics.

The constitutive relation of oil-water two-phase dispersed mixtures under the shear condition, with the oil volume fraction from 0 to 1 , was measured at different experimental conditions. In order to display the different between white oil and crude oil, the measurement results of white oil A and crude oil $\mathrm{B}$ are given. Figure 2a presents the relation between shear stress and shear rate of the white oil and water two-phase dispersed mixtures with the oil volume fraction of $0.1,0.2,0.4$, 0.6 and 0.8 . It shows that the white-oil-in-water and water-inwhite-oil mixtures showed different non-Newtonian fluid characteristics that divided into shear thickening and shear thinning. Figure $2 b$ displays the same experimental results of crude oil-water two-phase dispersed mixtures with the oil volume fraction of $0.1,0.2$ and 0.6 . Similarly, the constitutive relation of crude oil-water dispersed mixtures shows the same rule as white oil-water mixtures.

The power law fluid relationship is used to fitting the corresponded experimental results in order to analyze the non-Newtonian fluid characteristics of oil-water dispersed mixtures. The fitting parameters and regression correlation coefficient are displayed in Table 3. It can be found that the power law fluid model has a great accuracy to describe the oil-water dispersed mixtures where the value of regression correlation coefficient $\left(R^{2}\right)$ is bigger than 0.99 . In the other word, the relation between apparent viscosity and shear rate of oil-water dispersed mixture can be described in the type of the power law equation which could be useful to predict apparent viscosity accurately.

The flow behavior index $(n)$ displays the degree of nonNewtonian fluid characteristic. The sample shows
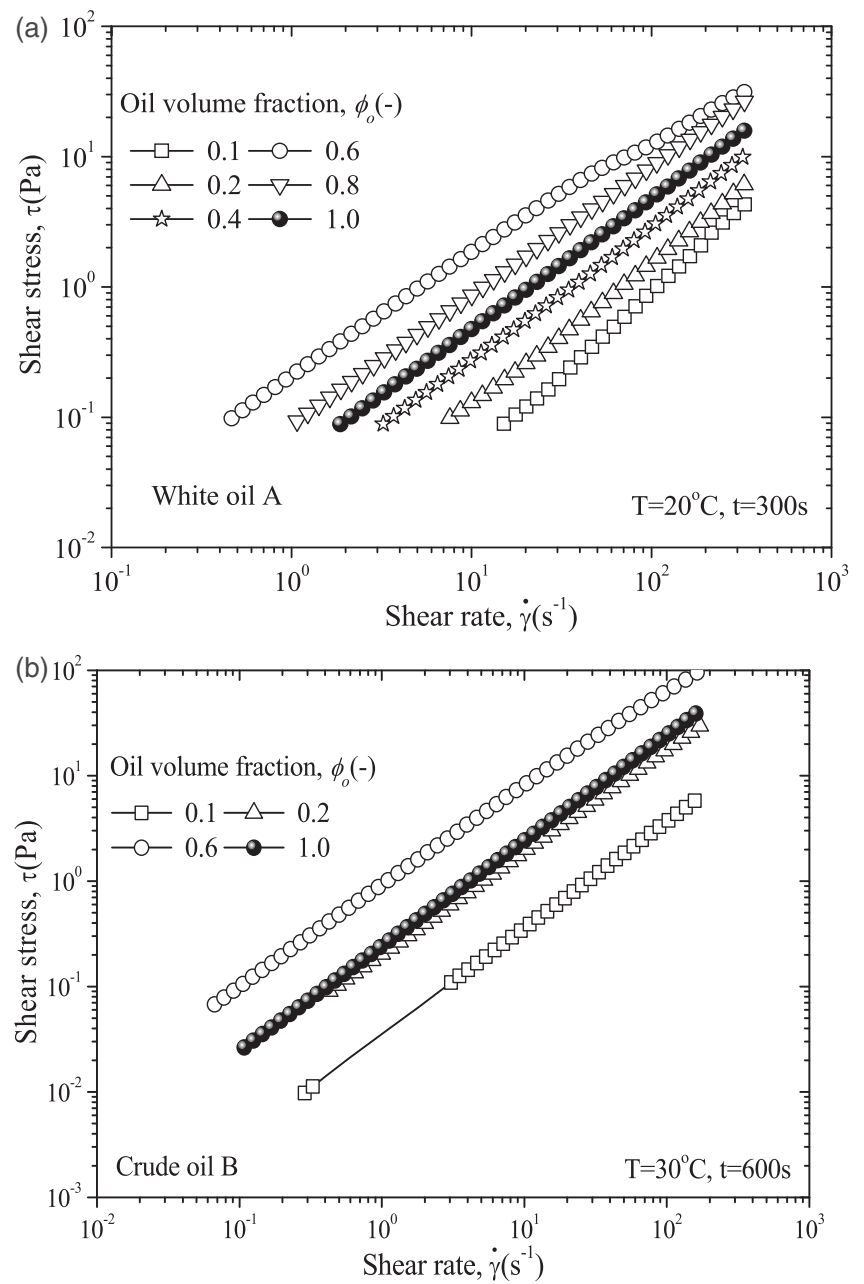

Figure 2. Constitutive relation of oil-water dispersed mixtures in different oil volume fractions.

Table 3. Fitting parameters in Power law fluid model of oil-water dispersed mixtures in Figure 2.

\begin{tabular}{lccccl}
\hline Oil type & $\Phi_{o}(-)$ & $\mathrm{m}\left(\mathrm{Pas}^{\mathrm{n}}\right)$ & $\mathrm{n}(-)$ & $\mathrm{R}^{2}(-)$ & Mixture type \\
\hline White oil A & 0.1 & 0.0025 & 1.2846 & 0.9994 & $\mathrm{O} / \mathrm{W}$ \\
& 0.2 & 0.0097 & 1.1029 & 0.9992 & $\mathrm{O} / \mathrm{W}$ \\
& 0.4 & 0.0261 & 1.0231 & 0.9998 & $\mathrm{O} / \mathrm{W}$ \\
& 0.6 & 0.2231 & 0.8687 & 0.9977 & W/O \\
& 0.8 & 0.0879 & 0.9889 & 1.0000 & W/O \\
Crude oil B & 1.0 & 0.0470 & 1.0000 & 1.0000 & Pure oil \\
& 0.1 & 0.0349 & 1.0110 & 1.0000 & $\mathrm{O} / \mathrm{W}$ \\
& 0.2 & 0.2057 & 0.9708 & 1.0000 & $\mathrm{O} / \mathrm{W}$ \\
& 0.6 & 0.9086 & 0.9370 & 0.9996 & W/O \\
& 1.0 & 0.2427 & 0.9995 & 1.0000 & Pure oil \\
\hline
\end{tabular}

Newtonian fluid behavior when $n=1$, and it shows shear thickening and shear thinning fluid behavior when $n>1$ and $n<1$, respectively. In Table 3, it can be see that the oilin-water dispersed mixtures present the shear thickening fluid behavior, and yet the water-in-oil dispersed mixtures present the shear thinning fluid behavior which can be also found for the stable emulsions. ${ }^{[30,31]}$

\section{Effect of the oil volume fraction}

The effect of dispersed phase volume fraction has been studied for a long time, and it is the main factor in the most of the apparent viscosity prediction models of stable 
emulsions. In this study, the relevant experiments with different kinds of conditions were done to obtain the effect of oil volume fraction on the apparent viscosity of the unstable oil-in-water and water-in-oil dispersed mixtures.

Figure 3 presents the changing relation between apparent viscosity and oil volume fraction of four kinds of oil-water dispersed mixtures at the fixed shear rate of $10 \mathrm{~s}^{-1}$. It can be seen that these four kinds of oil-water dispersed mixtures show the similar rule. The apparent viscosity increases as the increasing of oil volume fraction from zero to the phase inversion point firstly, and decreases as the continuous increasing oil volume fraction after the phase inversion point which is the limit of water continuous and oil continuous mixtures. In the other words, the apparent viscosity of oil-water dispersed mixtures reaches to its peak value around the phase inversion point. Differently, the oil volume fraction of white oil $\mathrm{A}$ is 0.5 at the phase inversion point, and the value is 0.6 of white oil $\mathrm{B}$, crude oil A and crude oil $\mathrm{B}$ on the similar experimental conditions.

Figure 4 displays the relative viscosity against the changing oil volume fraction in order to give the influence of the dispersed phase fraction on the viscosity of oil-water dispersed mixtures. It can be found that the relative viscosity is greater when water is the continuous phase, and the relative viscosity increases sharply as the increasing dispersed phase fraction. Also, the relative viscosity increases as the increasing dispersed phase fraction when oil is the continuous phase. However, the influence degree of the dispersed phase fraction on the relative viscosity has a great difference of oil-in-water and water-in-oil dispersed mixtures. Based on the experimental results, it can be concluded that the difference is due to the relative viscosity $\left(\eta_{d} / \eta_{c}\right)$ of the dispersed phase and the continuous phase.

\section{Effect of the oil viscosity}

In this section, the effect of the different dispersed phase or continuous phase viscosity on the apparent viscosity of oilwater dispersed mixture with the same continuous phase or dispersed phase is studied. Figure 5 presents the effect of the oil viscosity on the oil-in-water dispersed mixtures on the same prepared and experimental conditions where the stirring time on preparation is $180 \mathrm{~s}$ and the experimental temperature is $20^{\circ} \mathrm{C}$. It can be seen that the relative viscosity of white-oil$\mathrm{B}$-in-water dispersed mixtures is bigger than the corresponded white-oil-A-in-water dispersed mixtures with the same dispersed phase fraction. Conclusion, the dispersed phase viscosity has a great influence on the apparent viscosity of dispersed mixture which is not considered in the most of the existed apparent viscosity predication models. Figure 6 displays the effect of the oil viscosity on the relative viscosity of water-inoil dispersed mixtures. It shows that the different continuous phase viscosities, white oil $\mathrm{A}$ and $\mathrm{B}$, has a little influence on the apparent viscosity of dispersed mixtures with the same dispersed phase. As the comparative analysis, it is due to the little difference of the relative viscosity of dispersed phase to continuous phase.

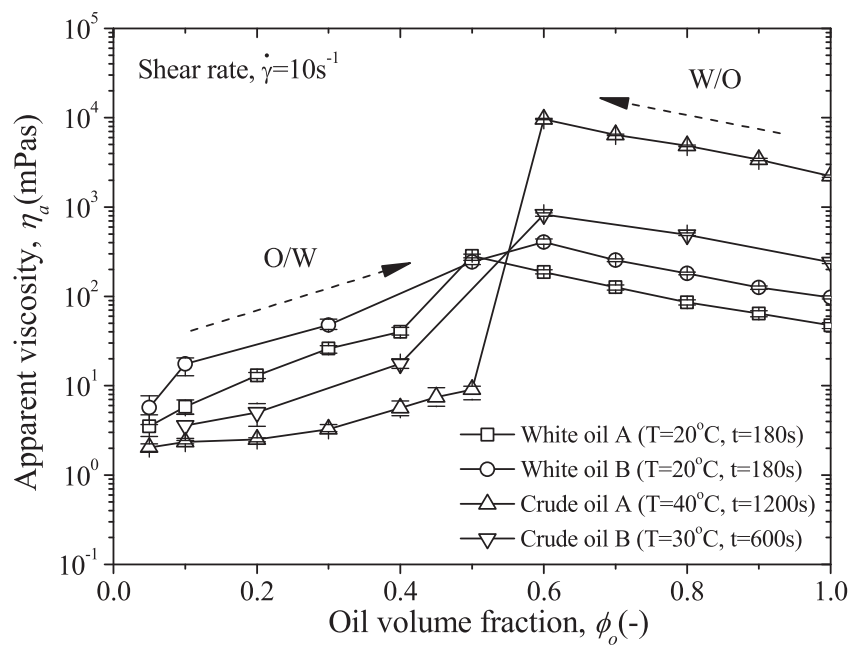

Figure 3. Apparent viscosity vs. oil volume fraction of experimental oils on different conditions.

\section{Effect of the dispersed phase distribution}

In our knowledge, the droplet size and its polydispersity of the dispersed phase are important in characterizing the stability of the dispersed mixtures. The droplets size and polydispersity of the dispersed phase in oil-water two-phase dispersed mixtures are determined by two opposite mechanisms of droplets breakup and coalescence when the mixtures under shearing condition. In this work, the different stirring time in preparing mixtures is used to obtain the different droplets size and polydispersity. The phenomenon of droplets coalescence and sedimentation is given to analyze the stability of the experimental oil-water dispersed mixtures. And then, the effect of the dispersed phase distribution on the rheological characteristics is studied in this section.

Figure 7 displays the stability of crude oil A and water two-phase dispersed mixtures with the different stirring time of $100 \mathrm{~s}$ and $300 \mathrm{~s}$ on the prepared section. The oil volume fraction is 0.6 , and the settling time after the preparation, displayed in the Figure, is $0,15 \mathrm{~min}$, and 3 hours in sequence. It can be found that the oil-water dispersed mixtures are very unsteady with a short stirring that these mixtures fast stratified after of short settling time. Comparation the phenomenon of stratified between Figure $7 \mathrm{a}$ and $7 \mathrm{~b}$, it shows that the stability of dispersed mixture can be enhanced with the increasing stirring time. And, the unstable characteristic of oil-water dispersed mixtures is consistent with the dispersed pipeline flow in petroleum engineering. Therefore, the research result of the rheological characteristics of unstable mixtures can be used in pipeline flow directly.

The microstructure of the prepared oil-water dispersed mixtures under different stirring time is given in Figure 8. It shows that the droplet size is smaller as the stirring time increased. The droplets coalescence and breakup will influence the rheological characteristics of the unstable oil-water dispersed mixtures greatly. The volume average droplet sizes are about $26,22,9$, and $4 \mu \mathrm{m}$ for the stirring time of 100 , 300,600 and 1200 s, respectively. 


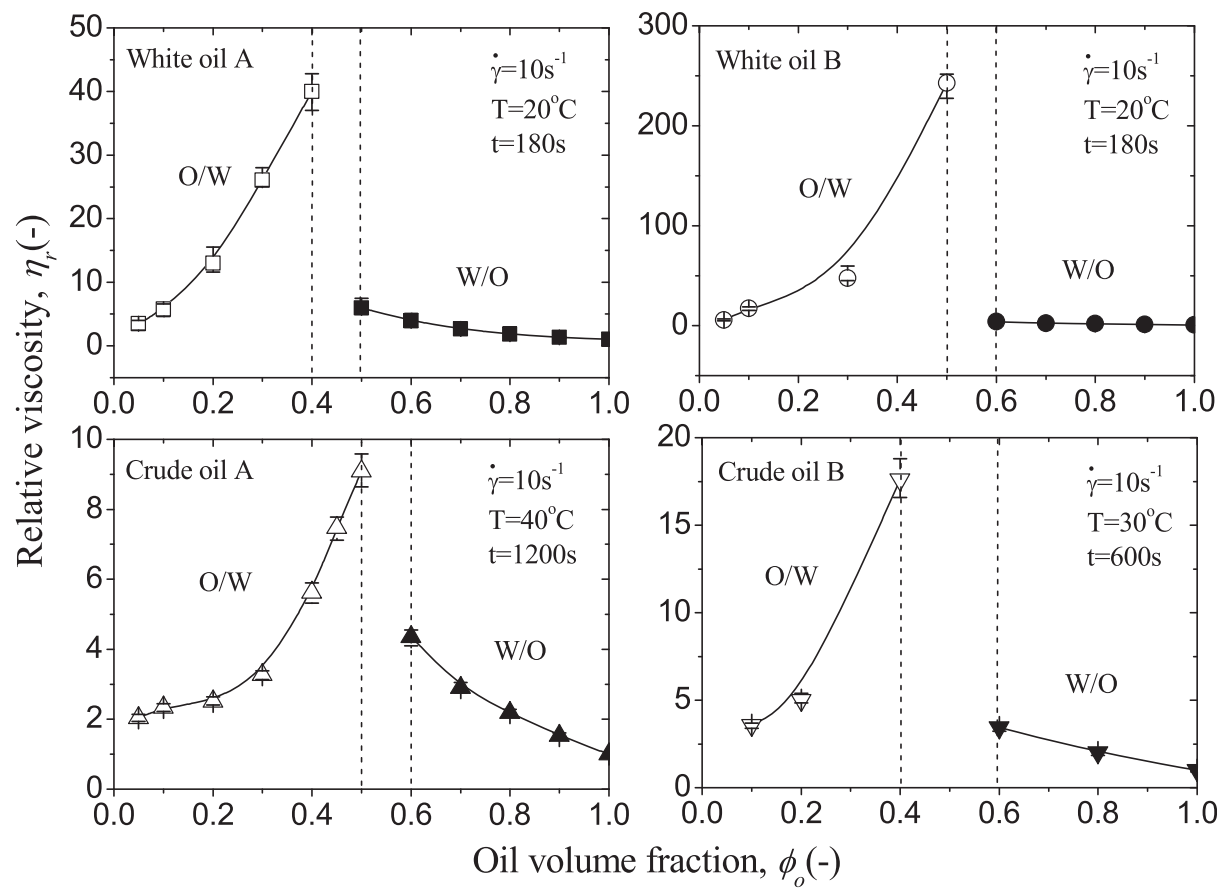

Figure 4. Relative viscosity vs. oil volume fraction of experimental oils on different conditions.

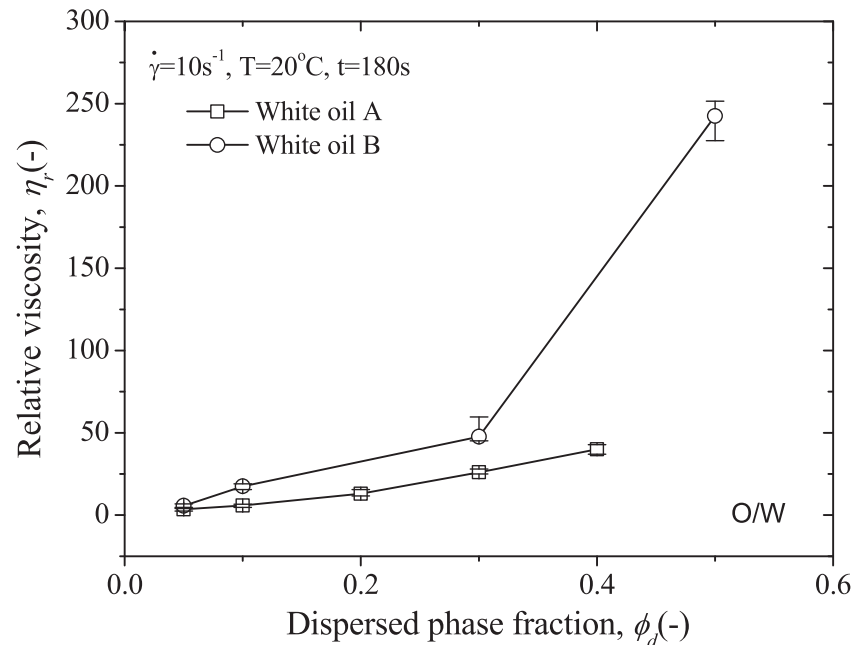

Figure 5. The effect of oil viscosity on the relative viscosity of oil-in-water dispersed mixtures.

Figure 9 presents the apparent viscosity of oil-water dispersed mixtures against the continuous shear rate under four different stirring time corresponding to Figure 8. All the dispersed mixtures display the same non-Newtonian fluid characteristic of shear thinning. The apparent viscosity increases as the increasing stirring time under the same shear rate. Especially, the value of apparent viscosity, when the stirring time is $1200 \mathrm{~s}$, is much bigger than the other three conditions. Based on the experimental data, the reason of the great difference is the different types of these mixtures. The continuous phase of the mixture prepared by stirring of $1200 \mathrm{~s}$ is oil, and the other three mixtures is water which can be found in their corresponding microstructures.

The apparent viscosity as a function of stirring time on a fixed shear rate $\left(\dot{\gamma}=10 \mathrm{~s}^{-1}\right)$ and the same oil volume fraction $\left(\Phi_{o}=0.6\right)$ is given in Figure 10. Clearly, the apparent viscosity of the oil-water dispersed mixtures keeps increasing as the

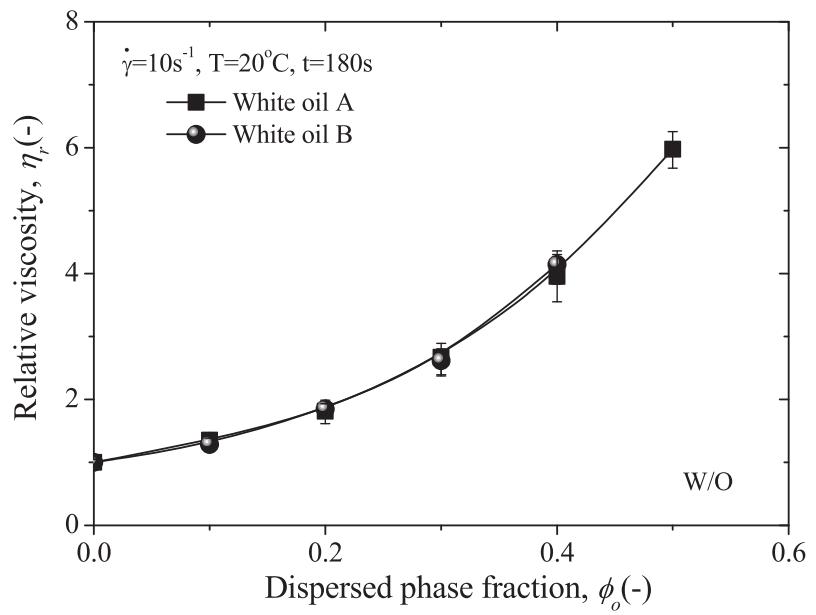

Figure 6. The effect of oil viscosity on the relative viscosity of water-in-oil dispersed mixtures.

stirring time increased. In the other word, the difference of the dispersed phase distribution has a great influence on the apparent viscosity of oil-water two-phase dispersed mixtures.

\section{Effect of the system temperature}

The system temperature has a great influence on the viscosity of any fluids, and the Arrhenius model is always used to describe the law of influence. In this section, the effect of temperature on the apparent viscosity of oil-water dispersed mixtures is studied.

Figure 11 displays the value of apparent viscosity as the changing shear rate at the different system temperatures of $30,40,50,60$ and $80^{\circ} \mathrm{C}$ for Crude oil $\mathrm{A}$ and water dispersed mixtures with the oil volume fraction of 0.6. It shows that the measurement temperature has a great influence on the value of apparent viscosity, but a little effect on the 
(a)

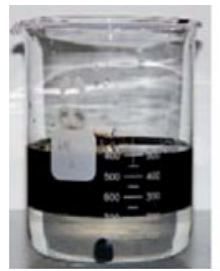

(b)
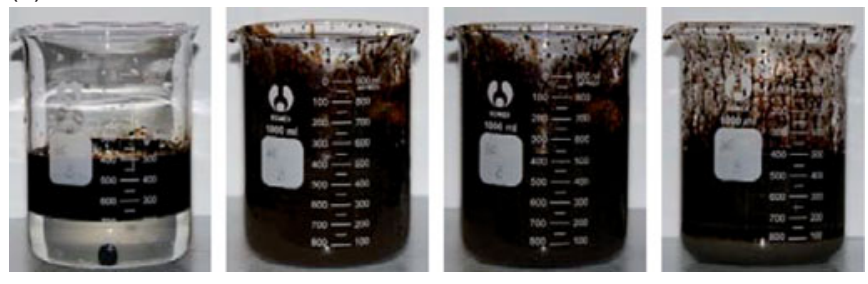

Stirring time, $\mathrm{t}=300 \mathrm{~s}$

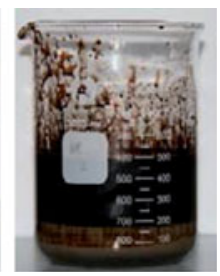

Stirring time, $\mathrm{t}=100 \mathrm{~s}$

Figure 7. Effect of the prepared stirring time on the steady of crude oil-A and water dispersed mixtures $\left(\Phi 0=0.6 ; \mathrm{T}=30^{\circ} \mathrm{C}\right.$; Settling time: before stirring, 0 , $15 \mathrm{~min}, 3$ hours).
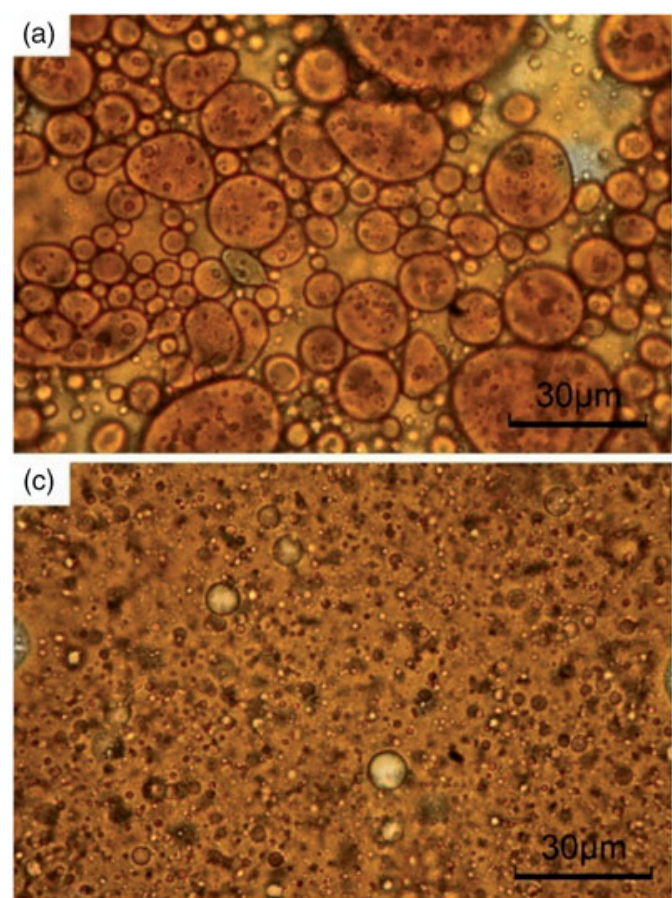

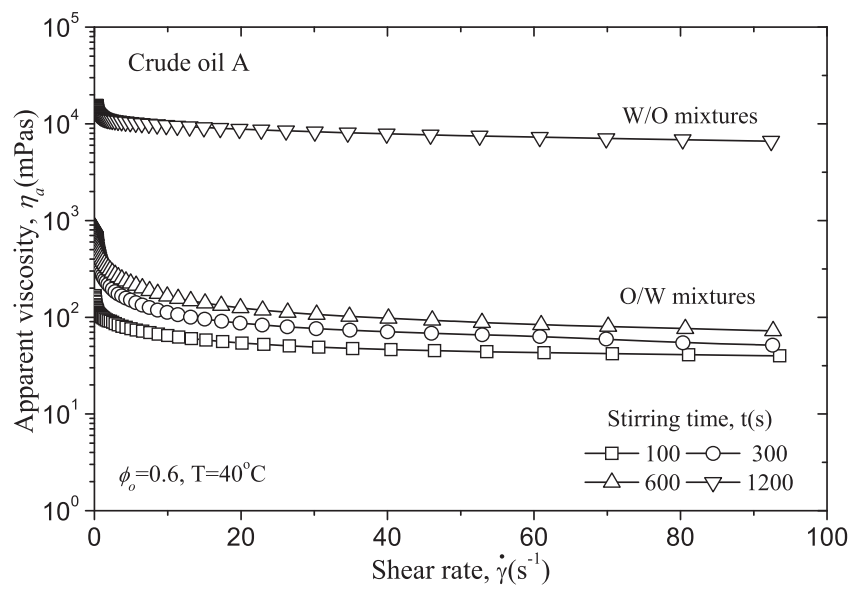

Figure 9. Apparent viscosity vs. shear rate of crude oil $A$ and water dispersed mixtures under the different stirring time of $100 \mathrm{~s}, 300 \mathrm{~s}, 600 \mathrm{~s}$ and $1200 \mathrm{~s}$ $\left(\Phi 0=0.6 ; \mathrm{T}=40^{\circ} \mathrm{C}\right.$.

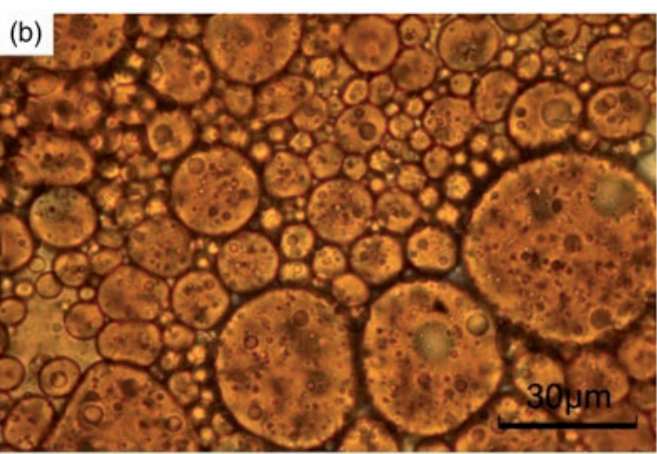

(d)

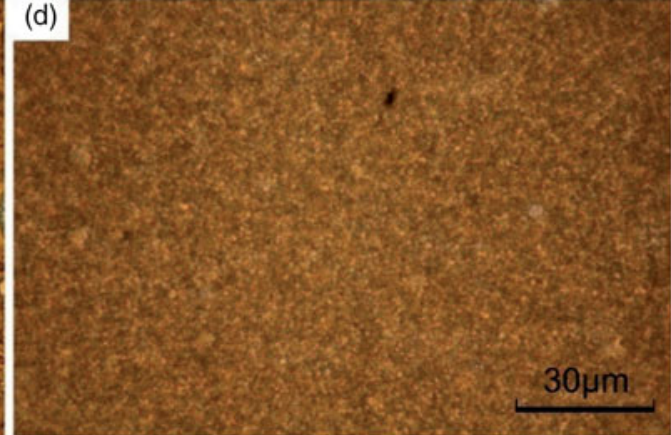

Figure 8. Microstructure $(100 \times)$ of the crude oil-A and water dispersed mixtures under the different stirring time of $100 \mathrm{~s}$ (a), 300s (b), 600s (c) and 1200s (d) $\left(\Phi 0=0.6 ; \mathrm{T}=30^{\circ} \mathrm{C}\right)$.

constitutive relation of the dispersed mixture which shows the shear thinning fluid characteristic all the time. Figure 12 presents the apparent viscosity at the function of system temperature on the several different experimental conditions. It can be found that the apparent viscosity keeps decreasing as the increasing temperature on the similar rule of exponent which can be found for pure oil also.

Figure 13 gives the relative viscosity as the function of system temperature in order to research the mechanism of action. It is found that the system temperature has a little influence on the relative viscosity of oil-water dispersed mixtures. Therefore, the effect of system temperature on the apparent viscosity of oil-water dispersed mixture is through the effect on the viscosities of the two single phases primarily. In conclusion, the apparent viscosity of oil-water dispersed mixture can be obtained if the viscosities of oil and water are given at the fixed temperature. The factor of temperature (T) can be neglected in function (1) if the factors of continuous phase viscosity and dispersed phase viscosity are included in this function.

\section{Development of prediction model}

The effects of dispersed phase volume fraction, viscosities of continuous and dispersed phases, dispersed phase 


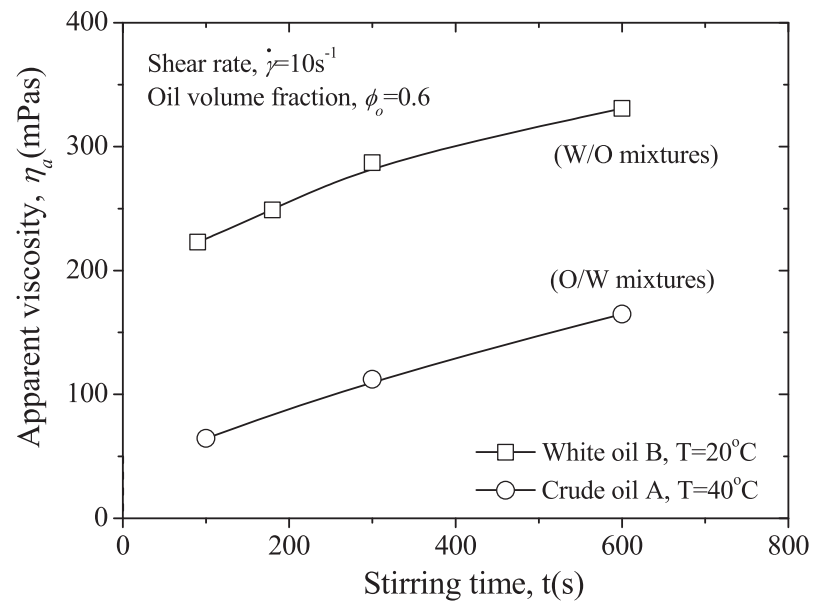

Figure 10. The changing rule of the apparent viscosity against the stirring time.

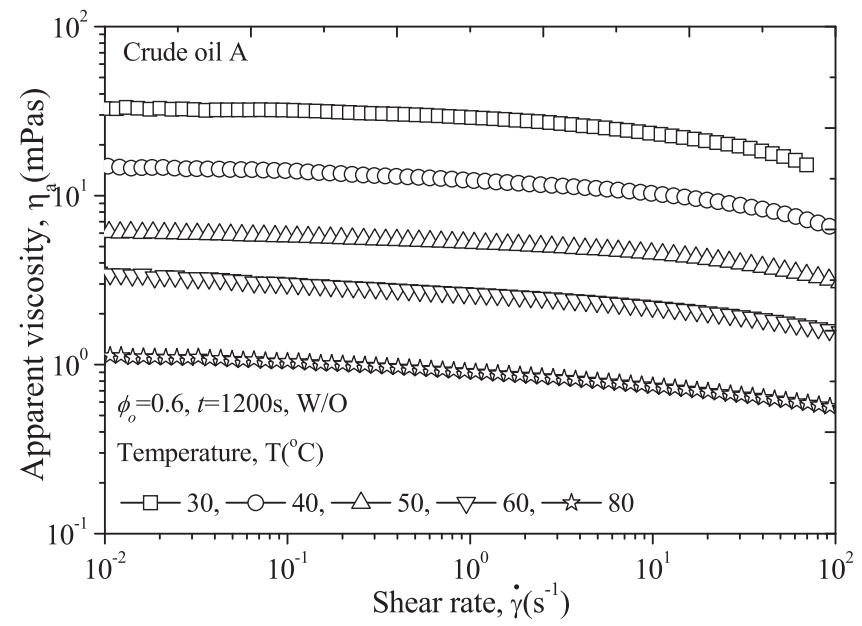

Figure 11. Apparent viscosity vs. shear rate at the different temperatures for oil-water dispersed mixtures prepared by the same condition $(\Phi 0=0.6, \mathrm{t}=1200 \mathrm{~s})$.

distribution and temperature on the apparent viscosity of oil-water two-phase dispersed mixtures has been displayed above. It shows that the rheological characteristic of unstable oil-water mixtures is different to the corresponded stable emulsions, specially, the kinds of non-Newtonian fluid characteristics. And, the apparent viscosity prediction model for the stable emulsions, which has been studied plenty, is unsuited for the unstable oil-water dispersed mixtures. In this section, a new apparent viscosity prediction model for unstable oil-water dispersed mixtures is obtained from the theoretical analysis of the experimental consequences. Basically, a series of characteristics due to the unstable of the oil-water mixtures, such as the non-Newtonian fluid characteristic, is considered in this model systematically. Also, the accuracy of this new model is analyzed which shows that it is suited for the unstable dispersed mixtures greatly.

\section{Develop a new prediction model}

The effect of the volume fraction of dispersed phase $\left(\Phi_{d}\right)$, viscosity of continuous phase $\left(\eta_{c}\right)$, viscosity of dispersed

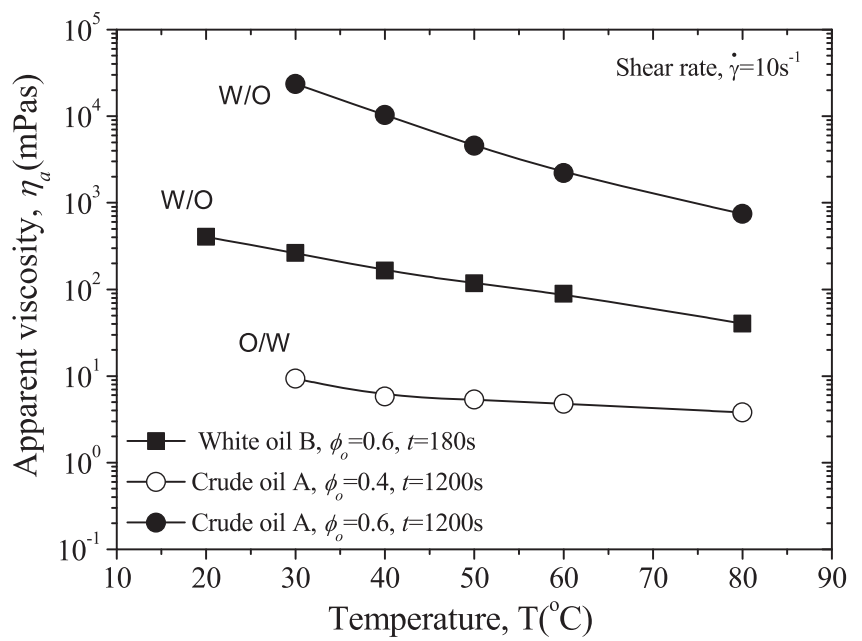

Figure 12. The effect of system temperature on the apparent viscosity for the different mixtures.

phase $\left(\eta_{d}\right)$, droplet distribution of dispersed phase $\left(d_{d}\right)$, temperature $(T)$, shear rate $\left(\gamma^{\prime}\right)$, density of continuous phase $\left(\rho_{c}\right)$, density of dispersed phase $\left(\rho_{d}\right)$ on the apparent viscosity can be rewritten as the relative viscosity $\left(\eta_{r}\right)$ below,

$$
\eta_{r}=f\left(\phi_{d}, \eta_{c}, \eta_{d}, d_{d}, T, \dot{\gamma}, \rho_{c}, \rho_{d}\right) .
$$

Clearly, the effect of the densities of continuous phase and dispersed phase on the apparent viscosity is through their influence on the dispersed phase distribution of the dispersed mixture. The effect function can be described,

$$
\eta_{r}=f\left(\phi_{d}, \eta_{c}, \eta_{d}, d_{d}\left(\rho_{c}, \rho_{d}\right), T, \dot{\gamma}\right) .
$$

In the experimental section, the effect of system temperature on the apparent viscosity of oil-water dispersed mixture has been researched. It shows that the effect of temperature on the apparent viscosity of the dispersed mixture is through the influence on the viscosities of the two single phases primarily. The apparent viscosity of oil-water dispersed mixture can be obtained if the viscosities of oil and water are given at the same temperature. Therefore, the factor of temperature can be neglected if the factors of continuous phase viscosity and dispersed phase viscosity are included in this function,

$$
\eta_{r}=f\left(\phi_{d}, \eta_{c}(T), \eta_{d}(T), d_{d}\left(\rho_{c}, \rho_{d}\right), \dot{\gamma}\right) .
$$

As the results in this work and others, the oil-water twophase dispersed mixture displays the different kinds of nonNewtonian fluid characteristics, and it can be described by the power law fluid model accurately. So, the mathematic relation between the apparent viscosity and shear rate can be displayed below,

$$
\eta_{r} \propto(\dot{\gamma})^{n-1} .
$$

here, $n$ is the flow behavior index in the power law fluid model.

Based on the theory of dimensional analysis, the factor of the dispersed phase viscosity $\left(\eta_{d}\right)$ can be described in the type of the relative relation between dispersed phase and continuous phase $\left(\eta_{d} / \eta_{c}\right)$. The effect of the dispersed phase 
distribution on the apparent viscosity of dispersed mixture is through the dispersed phase viscosity $\left(\eta_{d}\right)$. The effect of the dispersed phase viscosity and droplet distribution on the apparent viscosity can be showed below,

$$
\eta_{r} \propto\left(\frac{\eta_{d}}{\eta_{c}}\right)^{h} .
$$

here, $h$ is determined by the dispersed phase distribution and the ratio of the viscosity between dispersed phase and continuous phase. The value of $h$ is zero if the dispersed mixture is described as the fine stable emulsion. At any other conditions, $h<0$ if $\eta_{d} / \eta_{c}<1$ and $h>0$ if $\eta_{d} / \eta_{c}>1$. Also, the absolute value of $\mathrm{h}$ will be increased as the increasing unstable degree of the oil-water dispersed mixtures.

Therefore, the apparent viscosity prediction model of the oil-water dispersed mixture can be displayed below,

$$
\eta_{r}=f\left(\phi_{d}\right) *\left(\frac{\eta_{d}}{\eta_{c}}\right)^{h} *(\dot{\gamma})^{n-1} .
$$

The relationship between the apparent viscosity and dispersed volume fraction has been researched for a long time of the two-phase stable emulsions. There are two common types of exponential and power which are always used for the basic relation from Mooney ${ }^{[20]}$ and Brinkman ${ }^{[21]}$ respectively.

$$
\begin{gathered}
\eta_{r} \propto \exp \left(\frac{2.5 \phi_{d}}{1-k \phi_{d}}\right) \\
\eta_{r} \propto\left(1-\phi_{d}\right)^{-2.5}
\end{gathered}
$$

And then, the apparent viscosity prediction equation is concluded in these two types below,

$$
\begin{gathered}
\eta_{r}=\exp \left(\frac{2.5 \phi_{d}}{1-k \phi_{d}}\right) *\left(\frac{\eta_{d}}{\eta_{c}}\right)^{h} *(\dot{\gamma})^{n-1}, \\
\eta_{r}=\left(1-\phi_{d}\right)^{-2.5} *\left(\frac{\eta_{d}}{\eta_{c}}\right)^{h} *(\dot{\gamma})^{n-1} .
\end{gathered}
$$

Furthermore, it can be concluded that the nonNewtonian fluid characteristic of the oil-water dispersed mixtures is different just as the changed oil volume fraction based on the experimental consequences. Therefore, the effect of shear rate on the apparent viscosity can be substituted by the dispersed phase volume fraction. Also, this method has been introduced by the other theories in these researches of Mooney, ${ }^{[20]}$ Pal et al. ${ }^{[23]}$ and Dou et al., ${ }^{[26]}$ respectively. The effect factor of shear rate will be hided in the constant parameter $\left(k_{e}\right)$ of the apparent viscosity prediction model. The apparent viscosity prediction models, Equations (11) and (12), are changed as below,

$$
\begin{gathered}
\eta_{r}=\exp \left(\frac{2.5 \phi_{d}}{1-k_{e} \phi_{d}}\right) *\left(\frac{\eta_{d}}{\eta_{c}}\right)^{h}, \\
\eta_{r}=\left(1-k_{e}^{\prime} \phi_{d}\right)^{-2.5} *\left(\frac{\eta_{d}}{\eta_{c}}\right)^{h} .
\end{gathered}
$$

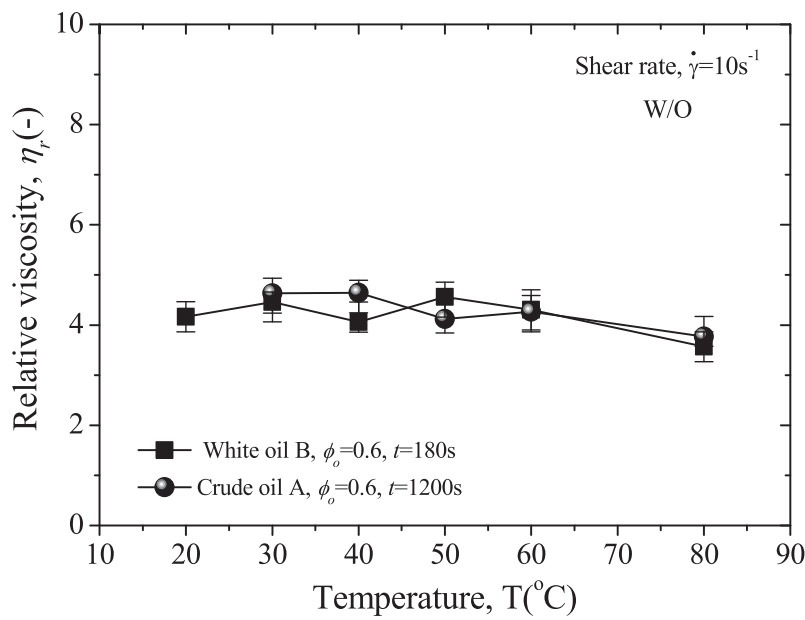

Figure 13. Relative viscosity as the function of system temperature.

here, $k_{e}$ and $k_{e}$ are determined by the shear rate and dispersed phase volume fraction, and, $k_{e}$ and $k_{e}$ are equal to 1 if the oil-water dispersed mixture characterized as the Newtonian fluid.

\section{Evaluation of the new model}

Figure 14 displays the predicted result of these new models for the apparent viscosity of oil-water dispersed mixture in this work including white oil $\mathrm{A} / \mathrm{B}$ and crude oil $\mathrm{A} / \mathrm{B}$. It can be observed that the predicted values and changing rules of these two new models are in line with all the experimental data greatly. And, the exponential type model (13) shows almost the same result as the power type model (14). Four previous models are used to take a comparison with the new models including all the kinds of equations of linear, exponential and power. It shows that the suggested prediction model is more accurate than these previous models.

In order to evaluate the applied range of these new models, the experimental data from literatures are chosen to carry out some comparison. Figure 15 presents the comparation results of the apparent viscosity between the predicted value and the experimental data from Dou and Gong [26] and Azodi et al. ${ }^{[32]}$ respectively. These chosen experimental data were obtained under the different conditions of shear rate, dispersed phase viscosity, prepared parameters and temperature. Moreover, the data include the two types of water-in-oil and oil-in-water emulsions. It can be seen in Figure 15 that the developed models predict the apparent viscosity in literatures accurately which demonstrates their applicability of these kinds of oil-water dispersed mixtures.

The average deviation is introduced to calculate the accuracy of these developed models.

$$
\theta=\frac{1}{n} \sum_{i=1}^{n}\left|\frac{\eta_{r p}-\eta_{r e}}{\eta_{r e}}\right| \times 100
$$

here, $\theta$ is the average deviation, in $\%, \eta_{r p}$ is the predicted relative viscosity and $\eta_{r e}$ is the experimental relative viscosity. Figure 16 displays the result of the error analysis of two developed models of the relative viscosity respectively. It can be seen that the predicted values of the relative viscosity coincide with 


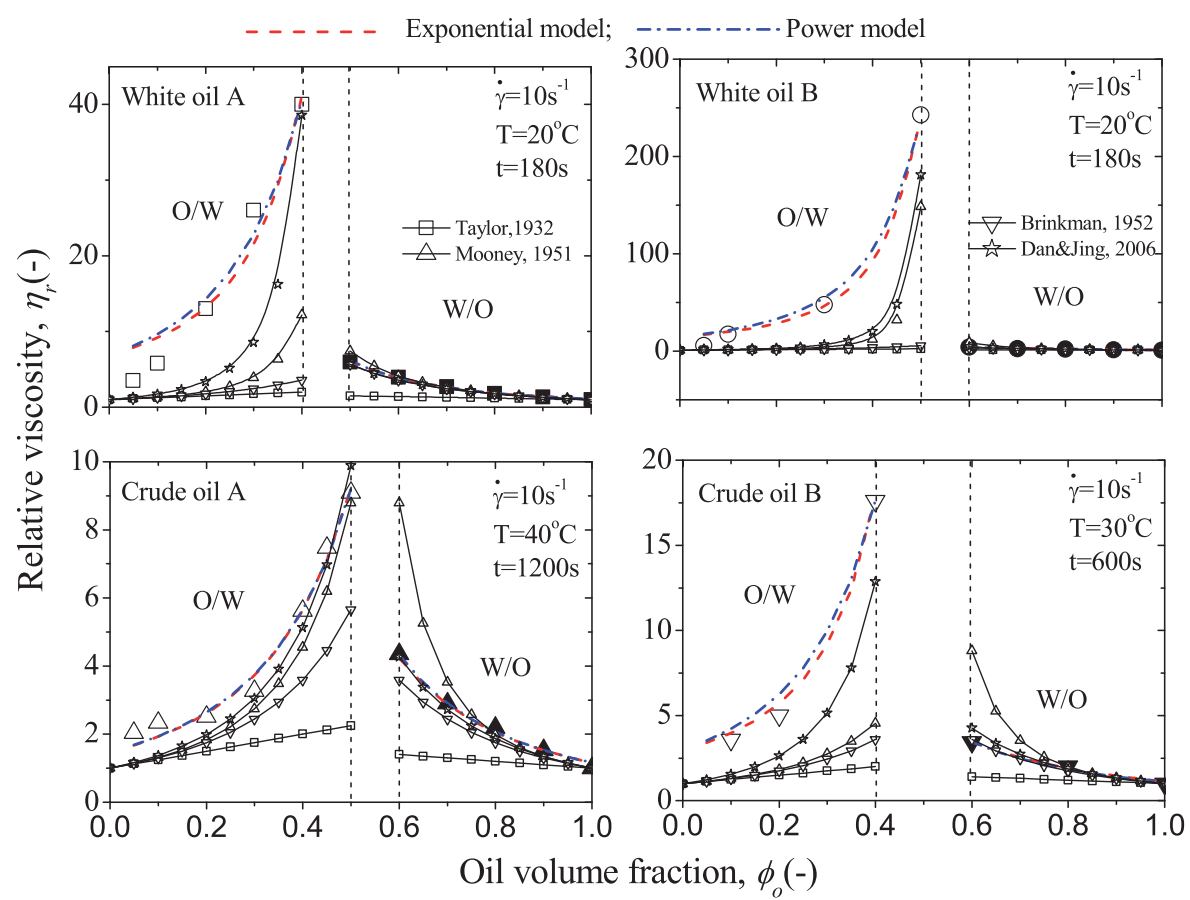

Figure 14. Comparation of the relative viscosity between the prediction value and experimental data in this work (white oil A/B, Crude oil A/B).
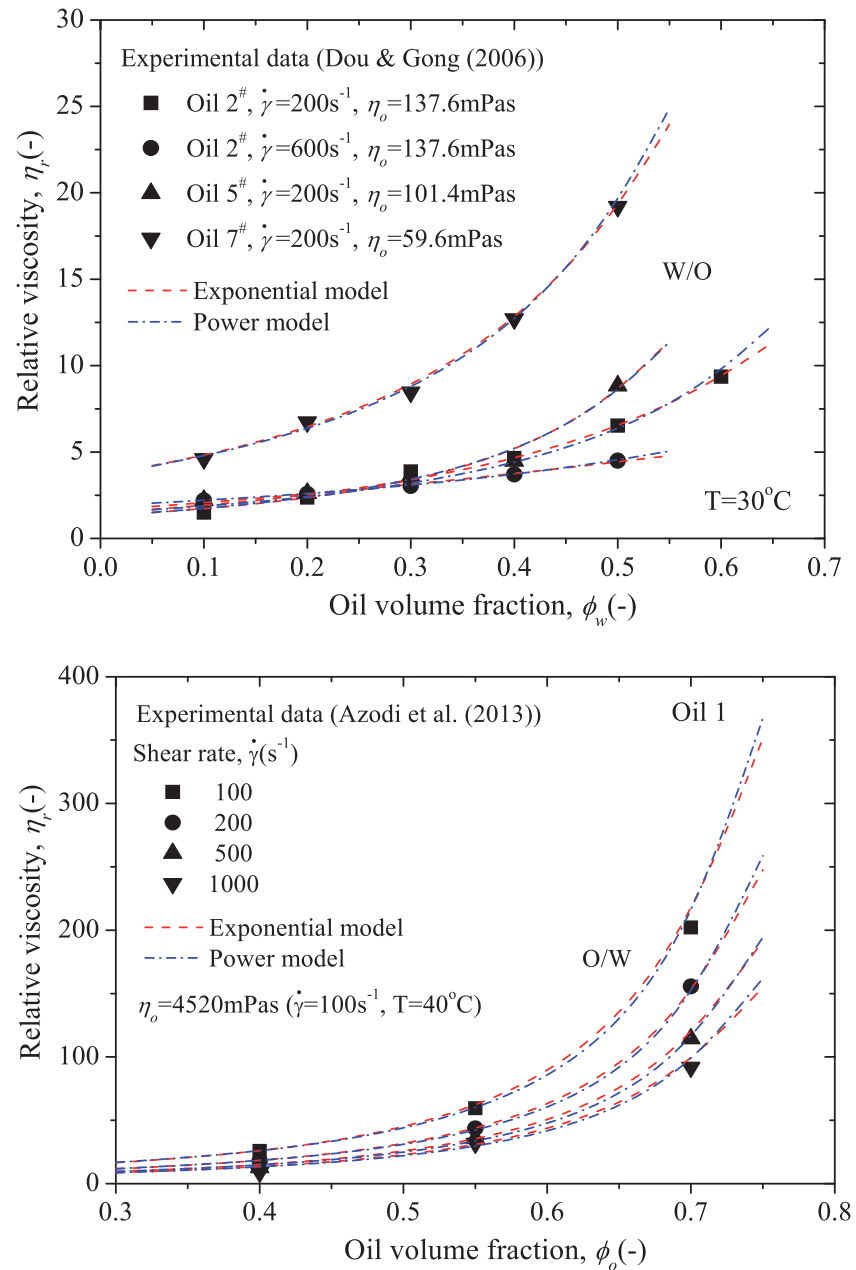

Figure 15. Comparation of the relative viscosity between the predicted value and the experimental data in literatures (Dou \& Gong (2006), Azodi et al. (2013)).
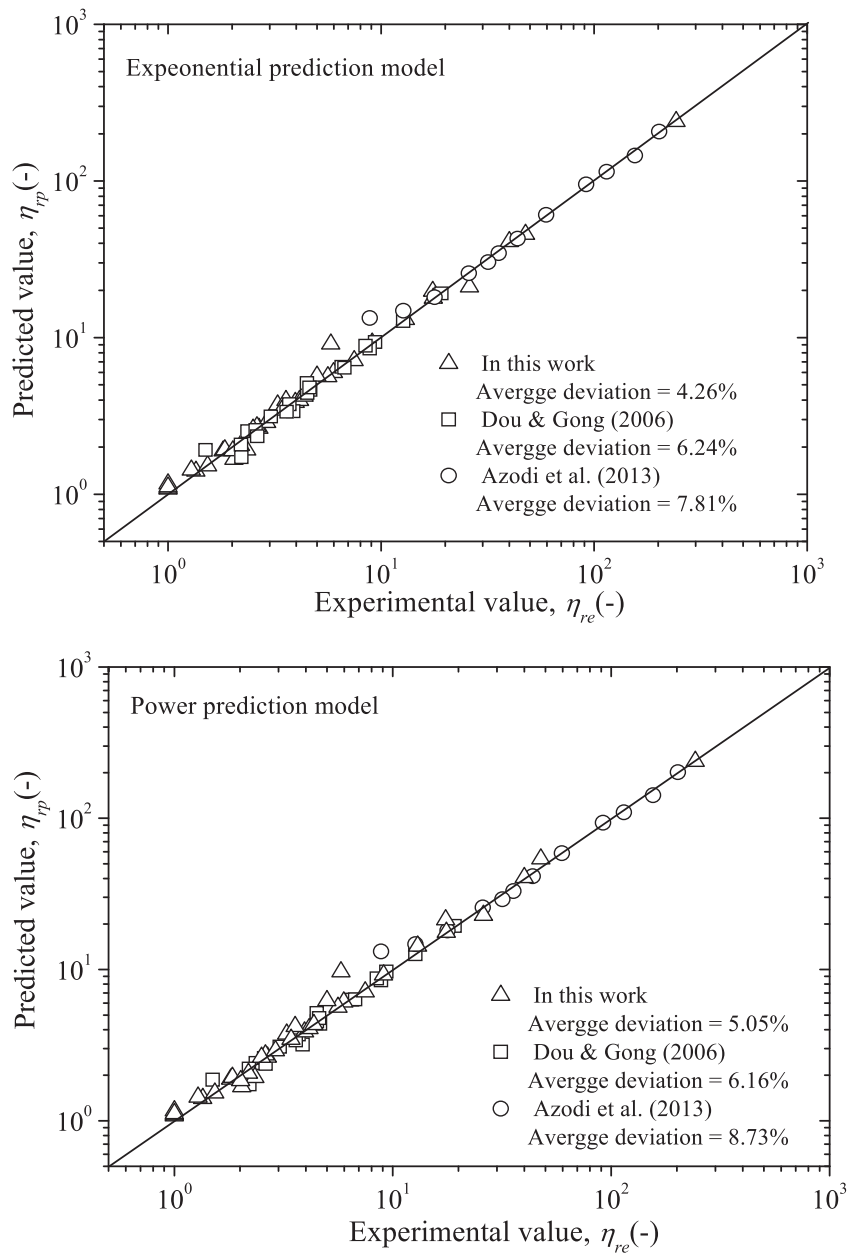

Figure 16. Error analysis of the two new models for the prediction on the relative viscosity. 
the experimental results well. The average deviations of the exponential type model are $4.26 \%, 6.24 \%$ and $7.81 \%$ for the experimental results in this work, Dou and Gong, and Azodi et al. respectively. And, the values of the average deviation are $5.05 \%, 6.16 \%$ and $8.73 \%$ of the power type model.

\section{Conclusion}

To improve the pipeline transportation of oil-water twophase dispersed mixtures, the theoretical analysis and experimental measurements were done to analyze the effects of the volume fraction of dispersed phase, viscosity of continuous phase, viscosity of dispersed phase, droplet distribution of dispersed phase, temperature, shear rate, densities of single continuous and dispersed phases on the apparent viscosity of oil-water unstable mixtures, which display the similar distributions as the mixtures in pipeline flow. The effect of unstable characteristics on the apparent viscosity of oil-water dispersed mixture is studied systematically for the first time.

Based on the experimental results, it can be concluded that the unstable oil-water dispersed mixtures always show the characteristic of non-Newtonian fluid, and appear the great different characteristics of the stable oil-water emulsion. The shear rate has a great influence on the apparent viscosity, particular for the water-in-oil mixtures. The power law fluid model can describe their constitutive relations. The effect of dispersed phase volume fraction on the apparent viscosity of the unstable mixtures displays the similar rules as the stable emulsions. Also, the influences of the dispersed phase distribution and viscosity on the apparent viscosity are studied through the corresponded experiments, which have not been considered on the previous researches. The difference of the dispersed phase distribution shows a great influence on the apparent viscosity of oil-water two-phase dispersed mixtures.

A new kind of prediction model is obtained to calculate the apparent viscosity of unstable oil-water dispersed mixtures in this work. The unstable and non-Newtonian fluid characteristics of oil-water two-phase dispersed mixtures are considered in these models to improve their range of application and the prediction accuracy. And, the effect of the dispersed phase viscosity is introduced in these developed models. Moreover, this kind of apparent viscosity prediction model is validated by using the experimental data from some other literatures included different kinds of oils such as white oil and crude oil. The average deviation is always less than $9 \%$ which is a great accuracy of apparent viscosity prediction. Finally, these developed apparent prediction models are proposed to calculate the apparent viscosity of different kinds of oil-water dispersed mixtures including stable and unstable emulsions. The pressure gradient of oilwater two-phase dispersed flow can be calculated more accurate to improve the design of the pipeline flow system.

\section{Acknowledgments}

This work described here is supported by the National Natural Science Foundation of China (51509235) and the Strategic Priority Research Program of the Chinese Academy of Science (XDB22030101).

\section{ORCID}

Jing-Yu Xu (iD) http://orcid.org/0000-0002-1058-2257

\section{References}

[1] Rodriguez, O.-M.-H.; Oliemans, R.-V.-A. Experimental Study on Oil-Water Flow in Horizontal and Slightly Inclined Pipes. Int. J. Multiphase Flow. 2006, 32, 323-343. DOI:10.1016/ j.ijmultiphaseflow.2005.11.001

[2] Lü, Y.; He, L.; He, Z.; Wang, A. A Study of Pressure Gradient Characteristics of Oil-Water Dispersed Flow in Horizontal Pipe. Energy Procedia. 2012, 16, 1111-1117. DOI:10.1016/ j.egypro.2012.01.177

[3] Schumann, H.; Tutkun, M.; Yang, Z.-L.; Nyda, O.-J. Experimental Study of Dispersed Oil-Water Flow in a Horizontal Pipe with Enhanced Inlet Mixing: Flow Patterns, Phase Distributions and Pressure Gradients. J. Petroleum Sci. Eng. 2016, 145, 742-752. DOI:10.1016/j.petrol.2016.06.005

[4] Xu, J.-Y.; Li, D.-H.; Guo, J.; Wu, Y.-X. Investigations of Phase Inversion and Frictional Pressure Gradients in Upward and Downward Oil-Water Flow in Vertical Pipes. Int. J. Multiphase Flow. 2010, 36, 930-939. DOI:10.1016/ j.ijmultiphaseflow.2010.08.007

[5] Rodriguez, I.-H.; Yamaguti, H.-K.-B.; Castro, M.-S.; Silva, M.-J.; Rodriguez, O.-M.-H. Drag Reduction Phenomenon in Viscous Oil-Water Dispersed Pipe Flow: Experimental Investigation and Phenomenological Modeling. AIChE J. 2012, 58, 2900-2910. DOI:10.1002/aic.12787

[6] Chen, X.-P.; Xu, J.-Y.; Zhang, J. A Simple Model for Predicting the Two-Phase Heavy Crude Oil Horizontal Flow with Low Gas Fraction. Chem. Eng. Comm. 2016, 203, 1131-1138. DOI: 10.1080/00986445.2016.1160227

[7] Al-Yaari, M.; Al-Sarkhi, A.; Hussein, I.-A.; Chang, F.; Abbad, M. Flow Characteristics of Surfactant Stabilized Water-in-Oil Emulsions. Chem. Eng. Res. Design. 2014, 92, 405-412. DOI: 10.1016/j.cherd.2013.09.001

[8] Wang, W.; Cheng, W.; Duan, J.-M.; Gong, J.; Hu, B.; Angeli, P. Effect of Dispersed Holdup on Drop Size in Oil-Water Dispersions: Experimental Observation and Population Balance Modeling. Chem. Eng. Sci. 2014, 105, 22-31. DOI:10.1016/ j.ces.2013.10.012

[9] Abubakar, A.; Al-Wahaibi, Y.; Al-Wahaibi, T.; Al-Hashmi, A.; Al-Ajmi, A.; Eshrati, M. Effect of Low Interfacial Tension on Flow Patterns, Pressure Gradients and Holdups of MediumViscosity Oil/Water Flow in Horizontal Pipe. Exp. Therm. Fluid Sci. 2015, 68, 58-67. DOI:10.1016/j.expthermflusci.2015.02.017

[10] Angeli, P.; Hewitt, G. Drop Size Distribution in Horizontal OilWater Dispersed Flows. Chem. Eng. Sci. 2000, 55, 3133-3143. DOI:10.1016/S0009-2509(99)00585-0

[11] Omer, A.; Pal, R. Pipeline Flow Behavior of Water-in-Oil Emulsions with and without a Polymeric Additive. Chem. Eng. Technol. Technol. 2010, 33, 983-992. DOI:10.1002/ ceat.200900297

[12] Zhang, J.; Xu, J.-Y.; Gao, M.-C.; Wu, Y.-X. Apparent Viscosity of Oil-Water (Coarse) Emulsion and Its Rheological Characterization during the Phase Inversion Region. J. Disp. Sci. Tech. 2013, 34, 1148-1160. DOI:10.1080/01932691.2012.735917

[13] Zhang, J.; Xu, J.-Y. Rheological Behavior of Oil and Water Emulsions and Theirs Flow Characterization in Horizontal Pipes. Can. J. Chem. Eng. 2016, 94, 324-331. DOI:10.1002/ cjce. 22377

[14] Barnes, H.-A. Rheology of Emulsions - A Review. Coll. Surf. A. 1994, 91, 89-95. DOI:10.1016/0927-7757(93)02719-U

[15] Derkach, S.-R. Rheology of Emulsions. Adv. Colloid Interface Sci. 2009, 151, 1-23. DOI:10.1016/j.cis.2009.07.001

[16] Einstein, A. Eine Neue Bestuimmung Der Molekular Dimensionen. Ann. Phys. 1906, 324, 9, 289-306. 
[17] Taylor, G.-I. The Viscosity of a Fluid Containing Small Drops of Another Fluid. Proc. Royal Soc. London. 1932, 138, 41-48. DOI:10.1098/rspa.1932.0169

[18] Richardson, V.-E.-G. Uber Die Viskositat Von Emulsionen. Kolloid Z. 1933, 65, 32-37. DOI:10.1007/BF01428855

[19] Guth, V.-E.; Simha, R. Untersuchungen Uber Die Viskositat Von Suspensionen Und Losungen. Kolloid Z. 1936, 74, 266-275. DOI:10.1007/BF01428643

[20] Mooney, M. The Viscosity of a Concentrated Suspension of Spherical Particles. J. Coll. Sci. 1951, 6, 162-170. DOI:10.1016/ 0095-8522(51)90036-0

[21] Brinkman, H.-C. The Viscosity of Concentrated Suspensions and Solutions. J. Chem. Phys. 1952, 20, 571-581. DOI:10.1063/ 1.1700493

[22] Krieger, I.-M.; Dougherty, T.-J. A Mechanism for nonNewtonian Flow in Suspensions of Rigid Spheres. Trans. Soc. Rheo. 1959, 3, 137-152. DOI:10.1122/1.548848

[23] Pal, R.; Rhodes, E. A Novel Viscosity Correlation for nonNewtonian Concentrated Emulsions. J. Coll. Interface Sci. 1985, 107, 301-307. DOI:10.1016/0021-9797(85)90181-X

[24] Ronningsen, H.-P. Correlations for predicting viscosity of w/o emulsions based on North Sea crude oils. SPE 28968, Houston, Texas, 1995.

[25] Pal, R. Novel Viscosity Equations for Emulsions of Two Immiscible Liquids. J. Rheo. 2001, 45, 509-520. DOI:10.1122/ 1.1339249
[26] Dou, D.; Gong, J. Apparent Viscosity Prediction of nonNewtonian Water-in-Crude Oil Emulsions. J. Petrol. Sci. Eng. 2006, 53, 113-122.

[27] Wen, J.-B.; Zhang, J.-J.; Wei, M. Effective Viscosity Prediction of Crude Oil-Water Mixtures with High Water Fraction. J. Petrol. Sci. Eng. 2016, 147, 760-770. DOI:10.1016/ j.petrol.2016.09.052

[28] Kundu, P.; Kumar, V.; Mishra, I.-M. Modeling the Steady-Shear Rheological Behavior of Dilute to Highly Concentrated Oil-inWater Emulsions: Effect of Temperature, Oil Volume Fraction and Anionic Surfactant Concentration. J. Petrol. Sci. Eng. 2015, 129, 189-204. DOI:10.1016/j.petrol.2015.03.008

[29] Bullard, J.-W.; Pauli, A.-T.; Garboczi, E.-J.; Martys, N.-S. A Comparison of Viscosity-Concentration Relationships for Emulsions. J. Coll. Interface Sci. 2009, 330, 186-193. DOI: 10.1016/j.jcis.2008.10.046

[30] Pal, R. Rheology of Simple and Multiple Emulsions. Current Opinion Coll. Interface Sci. 2011, 16, 41-60. DOI:10.1016/ j.cocis.2010.10.001

[31] Santos, R.-G.; Bannwart, A.-C.; Loh, W. Phase Segregation, Shear Thinning and Rheological Behavior of Crude Oil-inWater Emulsions. Chem. Eng. Res. Design. 2014, 92, 1629-1636. DOI:10.1016/j.cherd.2013.12.002

[32] Azodi, M.; Nazar, A.-R.-S. An Experimental Study on Factors Affecting the Heavy Crude Oil in Water Emulsions Viscosity. J. Petrol. Sci. Eng. 2013, 106, 1-8. DOI:10.1016/ j.petrol.2013.04.002 